\title{
SYMPOSIUM
}

\section{fMRI activation during a language task in adolescents with ASD}

\author{
TRACEY A. KNAUS,${ }^{1}$ ANDREW M. SILVER, ${ }^{1}$ KRISTEN A. LINDGREN, ${ }^{1}$ \\ NOUCHINE HADJIKHANI, ${ }^{2,3}$ AND HELEN TAGER-FLUSBERG ${ }^{1}$ \\ ${ }^{1}$ Department of Anatomy and Neurobiology, Boston University School of Medicine, Boston, Massachusetts \\ ${ }^{2}$ Martinos Center for Biomedical Imaging, Massachusetts General Hospital, Harvard Medical School, Boston, Massachusetts \\ ${ }^{3}$ Brain Mind Institute, EPFL, Lausanne, Switzerland
}

(Received December 7, 2007; Final Revision June 23, 2008; Accepted June 26, 2008)

\begin{abstract}
Autism spectrum disorder (ASD) is a neurodevelopmental disorder characterized by language and communication impairments, social impairments, and repetitive behaviors or restricted interests. Previous studies of semantic functions have found differences in semantic processing and differences in the activation of the language network in adults with ASD compared to controls. The goal of this study is to examine semantic functions in adolescents with ASD compared to typically developing adolescents. We utilized fMRI with a reading version of a response-naming task to investigate activation in 12 right-handed adolescent boys with ASD and 12 typically developing boys. Both groups performed the task at ceiling levels. Boys with ASD had significantly stronger activation than controls in Broca's area, which was less left lateralized in ASD individuals. Controls had a significant correlation between frontal and temporal language area activation in the left hemisphere, whereas ASD adolescents did not. Direct group comparisons revealed additional regions activated in the ASD group relative to the control group. These results suggest differences in semantic organization, approaches to the semantic task, or efficiency in semantic processing in ASD adolescents relative to typically developing adolescents. (JINS, 2008, 14, 967-979.)
\end{abstract}

Keywords: Autistic disorder, Functional MRI, Broca's area, Wernicke's area, Semantics, Asymmetry

\section{INTRODUCTION}

Autism spectrum disorder (ASD), a term including classic autism, pervasive developmental disorder-not otherwise specified (PDD-NOS), and Asperger syndrome, is a neurodevelopmental disorder characterized by impairments in language and communication, social deficits, and repetitive behaviors or intense interests (American Psychiatric Association, 1994). Although deficits in language and communication are one of the core features of ASD, the specific nature of these impairments remains unclear. Complicating this, the entire range of language abilities occurs in ASD, including individuals who never develop language to those

Correspondence and reprint requests to: Tracey Knaus Ph.D., Department of Anatomy \& Neurobiology, Boston University School of Medicine, 715 Albany Street L-814, Boston, MA 02118. E-mail: tknaus@ bu.edu who perform normal or above on standardized language tests (for review, Tager-Flusberg et al., 2005). Certain aspects of language, such as pragmatics are impaired in all individuals with ASD, regardless of functioning level (see TagerFlusberg et al., 2001). Other aspects of language, however, such as phonology, syntax, and semantics may not show impairment or may be impaired only in a subgroup (see Tager-Flusberg et al., 2001).

Semantic processing in ASD has been studied in older adolescents (15 years or older) and adults using several behavioral paradigms. Long-term memory studies have suggested semantic processing differences. Toichi and Kamio (2002) found semantic, compared to phonological or perceptual, processing of verbal items facilitated long-term memory in controls. In ASD, semantic facilitation did not occur, suggesting decreased use of semantic information. Mottron et al. (2001) demonstrated that when oriented to 
the semantic features, both groups had better recall than when oriented to phonological features or no orientation. However, when controls were given semantic cues at retrieval, recall was better than with phonological cues, whereas in ASD, semantic and phonological cues had the same effect. This further supports decreased use of semantic information in ASD. Similarly, another study found that controls had better long-term memory and increased verbal associations to concrete than abstract nouns and a correlation between recall and number of associations, which was not found in ASD (Toichi \& Kamio, 2003) and implies different semantic processing in the ASD group.

Semantic priming has also been used to examine semantic functioning in ASD. In a study of ASD individuals without early language delay, Kamio et al. (2007) showed semantic priming effects in controls, but not in ASD. Another priming study found no group differences, but found that when pictures, instead of words, were used as primes there was an increased priming effect in ASD, but not in controls (Kamio \& Toichi, 2000). Thus, in ASD, pictures may have an advantage over words in accessing meaning. Toichi and Kamio (2001) also found no differences in semantic priming in ASD compared to controls. A correlation was found between priming performance with performance IQ and Raven's Progressive Matrices in ASD, suggesting the contribution of non-verbal factors and the possibility of different strategies being used.

Functional neuroimaging has been used to investigate the neurobiological substrates of language in ASD. The first studies were PET and fMRI studies that used passive paradigms to explore auditory language processing. These studies found decreased temporal activation and decreased left lateralization of activation in autism compared to controls (Boddaert et al., 2003, 2004; Gervais et al., 2004; Müller et al., 1998, 1999).

Several studies have examined semantics or syntax using sentences in ASD adults. Müller and colleagues studied sentence production compared to sentence repetition. In one study, both groups had activation in the left inferior/middle frontal gyrus with left lateralization in the perisylvian region; controls also had activation in the left inferior temporal region (Müller et al., 1999). In another study, there was decreased left BA 46 and left thalamus activation in the autistic group relative to controls (Müller et al., 1998). Another group, focusing on syntactic processing during a visually presented sentence task, found increased posterior activation (left superior temporal gyrus) and reduced activation in frontal language areas (left inferior frontal gyrus) in autism compared to controls (Just et al., 2004). There was also decreased functional connectivity between anterior and posterior language regions. The ASD's task performance was faster and less accurate than controls'. Similar to behavioral findings, Kana et al. (2006) demonstrated activation in the ASD group in parietal and occipital imageryrelated regions in low- and high-imagery sentences, whereas controls had more activation in these regions during highrelative to low-imagery sentences. For their task, partici- pants indicated whether high- and low-imagery sentences were true or false and there were no group differences in performance.

Two fMRI studies focused on semantic processing of words in ASD and suggested atypical semantic processing or organization. Harris et al. (2006) demonstrated less activation in Broca's area and increased middle temporal gyrus activation in ASD relative to controls. The ASD group also showed similar activation in Broca's to the semantic and perceptual task, whereas controls had activation in this region only during the semantic task. Subjects indicated whether a visually presented word was positive or negative compared with a case decision of the same words, with similar performance in both groups. Gaffrey et al. (2007) had subjects determine whether visually presented words belonged to a given category and contrasted this with subjects indicating whether a specified letter occurred in letter strings. The control group was more accurate than the ASD group for the category task. The ASD group compared to controls had increased extrastriate visual cortex activation, which corresponded to increased errors on the semantic task. ASD individuals also had smaller activation clusters than controls in left inferior frontal regions, however, direct group comparisons did not reveal this difference.

The purpose of this study was to investigate semantic processing in adolescents with ASD and typically developing adolescents, utilizing fMRI. We used a visually presented response-naming task (Bookheimer et al., 1997). Almost no previous semantic fMRI tasks in ASD have involved language production and to our knowledge, this is the only study that has used a semantic task involving semantic integration and word generation. We chose a task that each individual could easily and accurately perform so that differences in activation between the groups could not be attributed to differences in performance levels (Bookheimer, 2000). fMRI semantic studies have been performed mainly in adults. To our knowledge, this is the first study to examine language activation patterns in ASD adolescents as young as 11 years old. Broca's and Wernicke's areas play key roles in semantic functions (for reviews, Bookheimer, 2002; Foundas, 2001; Vigneau et al., 2006). In addition, functional neuroimaging studies in ASD have demonstrated differences in these regions during semantic tasks, with several studies reporting decreased Broca's activation (Gaffrey et al., 2007; Harris et al., 2006; Just et al., 2004; Kana et al., 2006) and some finding increased Wernicke's area activation (Harris et al., 2006; Just et al., 2004). We therefore hypothesized that ASD individuals would have decreased left frontal language activation and increased activation of left temporal language regions. These prior studies, however, did not involve language generation, which relies heavily on Broca's area; so alternatively, we might not expect to find group differences in Broca's activation with this task. Behavioral and imaging studies have suggested different semantic organization or strategies in semantic processing. Based on these findings, we predicted that 
Table 1. Descriptive characteristics of participants. Mean, standard deviation, and range of demographic variables for each group

\begin{tabular}{|c|c|c|c|c|}
\hline \multicolumn{5}{|c|}{ Subject Demographics } \\
\hline & \multicolumn{2}{|c|}{ Controls $(n=12)$} & \multicolumn{2}{|c|}{$\operatorname{ASD}(n=12)$} \\
\hline & Mean & Range & Mean & Range \\
\hline Age & $14.94(2.71)$ & $11.5-19.8$ & $15.46(2.48)$ & $11.4-19.8$ \\
\hline Handedness & $18.33(4.58)$ & $+10-+23$ & $17.25(5.67)$ & $+3-+24$ \\
\hline Verbal IQ & $123.17(14.57)$ & $101-149$ & $106.08(21.47)$ & $67-136$ \\
\hline Non-Verbal IQ & $115.25(9.17)$ & $99-132$ & $102.92(15.23)$ & $70-121$ \\
\hline Full-Scale IQ & $122.25(11.10)$ & $100-136$ & $105.42(19.35)$ & $64-128$ \\
\hline CELF receptive & $116.33(11.55)$ & $94-131$ & $103.33(23.88)$ & $66-137$ \\
\hline CELF expressive & $108.92(8.52)$ & $91-123$ & $93.50(21.15)$ & $62-120$ \\
\hline CELF total & $113.92(9.69)$ & $95-130$ & $98.25(23.86)$ & $62-132$ \\
\hline ADOS social & & & $8.67(3.14)$ & $4-13$ \\
\hline ADOS communication & & & $2.92(1.24)$ & $1-5$ \\
\hline
\end{tabular}

the ASD group compared to typically developing adolescents would rely on different cortical areas during the semantic task.

\section{MATERIALS AND METHODS}

\section{Participants}

Participants included 12 adolescents with ASD (autism, Asperger syndrome, or PDD-NOS) and 12 typically developing adolescents, ages 11-19 years. All participants were male, monolingual (English), and right-handed based on writing hand, self-report, and a modified version of the Dean handedness inventory (Piro, 1998). The modified Dean handedness consists of 12 unimanual tasks and scores range from -24 , indicating complete left-handedness, to +24 , indicating complete right-handedness.

Participants were administered the Kaufman Brief Intelligence Test (K-BIT-II; Kaufman \& Kaufman, 2004) to assess IQ, and the Clinical Evaluation of Language Fundamentals (CELF-III; Semel et al., 1995) to assess language abilities. Four subtests of the CELF-III were administered: Concepts and Directions, Word Classes (Receptive language subtests), Formulated Sentences, and Recalling Sentences (Expressive language subtests).

For ASD subjects, diagnosis was based on DSM-IV criteria (American Psychiatric Association, 1994) using the Autism Diagnostic Interview-Revised (ADI-R; Lord et al., 1994) and the Autism Diagnostic Observation Schedule (ADOS; Lord et al., 2000). In addition, an expert clinician confirmed that all individuals met criteria for ASD. Individuals with frank neurological damage, with a known genetic disorder, who were born prematurely (less than 35 weeks), or who had seizures within the last three years were excluded. Typically developing individuals had no history or current diagnosis of developmental, learning, psychiat- ric, or neurologic disorders. See Table 1 for participant details.

Subjects 18 years and older provided informed written consent prior to participation. For subjects under 18 years old, parents gave informed written consent and children provided informed written or verbal assent prior to participation. All data in this manuscript were collected in compliance with the Boston University School of Medicine Institutional Review Board.

\section{MRI Acquisition}

All participants practiced in a mock scanner prior to the actual MR scanning. Images were acquired on a Philips 3 Tesla Intera scanner. Volumetric T1-weighted images were obtained as a series of 95-110,1.4 mm gapless axial images, aligned parallel to the intercommisural plane. Threedimensional MPRage was used with technical factors of: $T R=7.3 \mathrm{~ms}, T E=3.4 \mathrm{~ms}, \mathrm{FOV}=230 \mathrm{~mm}$, pixel matrix $=$ $256 \times 256$, flip angle $=8^{\circ}$. Two FE-EPI axial sequences aligned parallel to the intercommisural plane were acquired. fMRI scans were acquired using Blood Oxygen Level Dependent (BOLD) contrast with the following parameters: $T R=2000 \mathrm{~ms}, T E=35 \mathrm{~ms}, F O V=230 \mathrm{~mm}$, pixel matrix $=128 \times 128$, flip angle $=90^{\circ}, 36$ contiguous slices, slice thickness $=3.5 \mathrm{~mm}$.

\section{fMRI Task}

A block-design was used with a reading version of a response-naming task (Bookheimer et al., 1997) and a control letter-judgment task. During the response-naming task, subjects were shown a three-word phrase (e.g., keeps hands warm) and asked to think of what word was being described (e.g., gloves). They then chose, by pressing a button, from two displayed options, the word that best matched what 
they had thought of. For the control task, three strings of letters were presented and subjects indicated, with a button press, whether the letters were in upper or lower case. This task was chosen so that areas related to primary visual processing and motor areas related to the button press could be subtracted out of the language activation. For the stimuli used see the Appendix.

The stimuli were presented in red lettering on a black background using E-Prime software (http://www.pstnet. com/products/e-prime/). Prior to scanning, a practice session in the mock scanner was done, during which each subject performed one run consisting of different stimuli from those used in the actual scanning. During scanning, 2 functional runs were completed, each consisting of three blocks of response-naming and three blocks of the control task. Each block was 28 seconds and consisted of 4 trials, resulting in 48 trials across the two runs. A trial was presented every six seconds, with the three-word phrase or letter strings presented for 3.5 seconds, a blank screen for 0.2 seconds, the two word choices or the words upper and lower displayed for 2 seconds, and a blank screen for 0.3 seconds. At the beginning of each block a crosshair was presented for 4 seconds.

\section{Analyses}

fMRI analyses were carried out using Neurolens (www. neurolens.org). The first 2 volumes of each run were discarded to allow for magnet stabilization. Each run was motion corrected using a volume registration algorithm in which each volume was co-registered to a target volume (volume 85 of each run) (Cox \& Jesmanowicz, 1999). For each run, the output files from motion correction were examined to ensure that there was not significant motion. Subjects with movement in any direction greater than $2 \mathrm{~mm}$ or 2 degrees were excluded. To test for group differences in movement, the mean of the absolute value of translations and rotations across each run was calculated for each direction for each subject. A MANOVA was performed with the mean translation and rotation in each of the 3 directions for each run as dependent variables and group as the independent variable. This revealed no significant group differences in motion for any direction for either run $(F(12,11)=$ 2.36, $p>.05)$. Spatial smoothing was also performed on each functional run, using a 3-D Gaussian kernel with 6-mm full width at half-max.

For individual analyses, a general linear model (GLM) fitting the task block's time vector convolved with a gamma variate estimate of hemodynamic response was performed for each run, resulting in an activation map (the $-\log$ probability map which corresponds to the $t$-statistic), a map of the effect, and a map of the standard error of the effect. The words task and a baseline plus drift were modeled. The motion correction parameters for translations and rotations in each direction were included as regressors to improve the model. The group analysis function (Worsley et al., 2002) was used with fixed effects, to combine acti- vation and baseline for the two runs in each individual. For this, the maps of the effect and standard error of the effect for each individual run were utilized to generate a $-\log p$, effect, and standard error effect map for the two runs together. Because frontal and temporal regions are critical for semantic processing and to better account for individual differences in anatomy, activation within these regions was examined in individuals. To control for multiple comparisons, Bonferroni correction was used with the combined activation map for each participant thresholded to $p \leq 10^{-7}$, which was overlaid on each subject's respective high-resolution T1-image. Regions of interest (ROIs) were anatomically defined using well-established anatomical landmarks and all measurements were done by 1 rater (TAK) experienced in anatomically defining these regions (see Knaus et al., 2004, 2006, 2007). ROIs were defined in the sagittal plane. Frontal language areas (pars triangularis and pars opercularis) were bounded anteriorly by the anterior horizontal ramus of the Sylvian fissure, posteriorly by the pre-central sulcus, and superiorly by the inferior frontal sulcus. Activation in both banks of all of these gyri was included (Fig. 1a). Temporal language areas (pSTG, including PT) were bounded anteriorly by the most anterior Heschl's sulcus, posteriorly by the most posterior point of the Sylvian fissure, and superiorly by the horizontal ramus of the Sylvian fissure. When the Sylvian fissure gently sloped upward, the knife-cut method (Witelson \& Kigar, 1992) was utilized (Fig. 1b). Percent signal change was calculated in both regions in the right and left hemisphere as (mean of the modeled effect/mean of the baseline effect) $* 100$. To examine differences in percent signal change, a repeated measures MANOVA was computed with the percent signal change of each ROI as dependent variables, hemisphere as the repeated measure, and group as the independent variable.

An asymmetry quotient (AQ) of the percent signal change was calculated for each ROI. The AQ was calculated as (left percent signal change - right percent signal change)/ (left percent signal change + right percent signal change), with positive AQ indicating higher percent signal change in the left and negative AQ indicating higher percent signal change in the right. A MANOVA was performed to examine differences in degree of AQ with group as the independent variable and AQ of frontal and temporal areas as dependent variables.

The relationship between percent signal change and behavioral measures was examined within each group using Pearson correlations. The relationship between percent signal change of each ROI with CELF-III receptive and expressive standard scores was examined. Correlations between percent signal change of each ROI with age, verbal IQ (VIQ), and non-verbal IQ (NVIQ) measures from the KBIT-II were computed. The relationship between percent signal change of each ROI was also examined. In the ASD group, correlations between percent signal change of each ROI with ADOS communication and social scores were examined. 


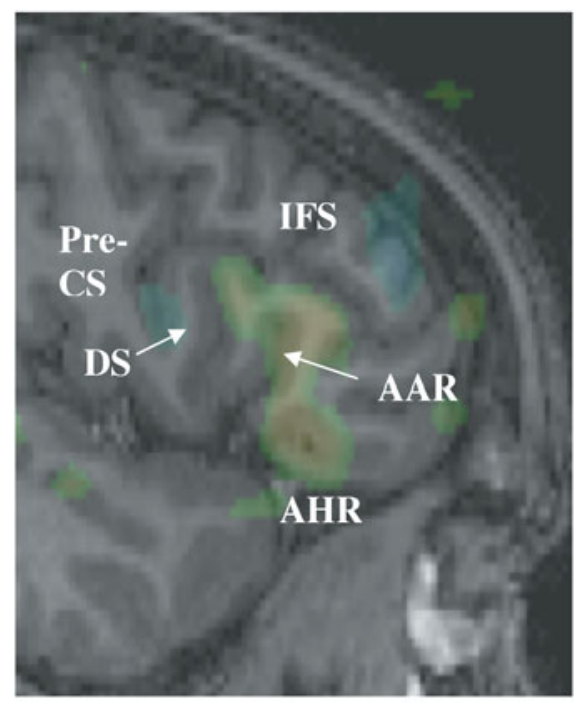

(a)

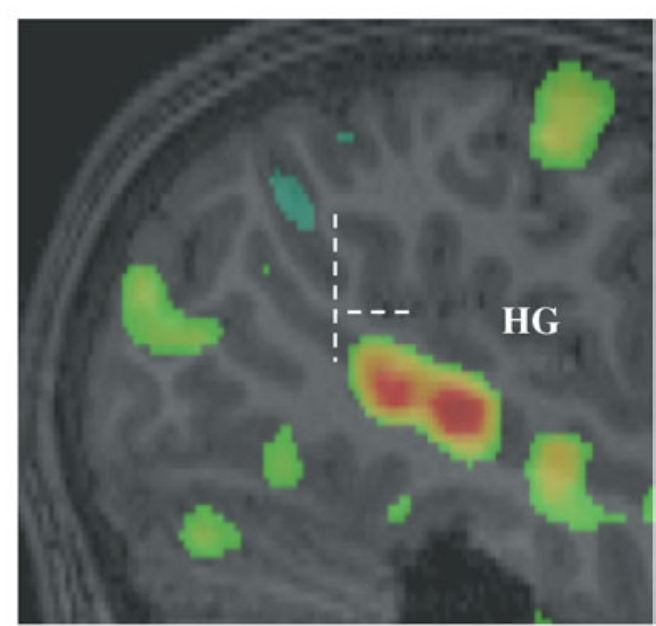

(b)

Fig. 1. (a) Boundaries used for frontal language ROI. All activation between pre-central sulcus and anterior horizontal ramus, bounded superiorly by the inferior frontal sulcus, was included. Pre-CS $=$ Pre-Central Sulcus, DS $=$ Diagonal Sulcus, IFS = Inferior Frontal Sulcus, AAR = Anterior Ascending Ramus, AHR = Anterior Horizontal Ramus. (b) Boundaries used for temporal language ROI. Dashed lines indicated posterior boundary, the end of the Sylvian fissure and the superior boundary, the horizontal ramus of the Sylvian fissure. Heschl's sulcus was the anterior boundary. $\mathrm{HG}=$ Heschl's gyrus.

For the group analysis, we computed a transformation matrix by fitting the first functional run of each subject to a group averaged EPI brain in MNI space. This transformation matrix, which resampled the fMRI acquisition voxels to 2-mm isotropic voxels, was then applied to the effect and standard error of the effect maps from the combined runs for each subject. These transformed effect and error maps were used in the group analysis with mixed effects. A block design GLM was fitted to all the effect maps for an individual group. The effect size was then divided by the residual standard error to produce a $t$-map, which was converted to a $-\log \mathrm{p}$ map. Cluster size thresholding was used to adjust for multiple comparisons (Forman et al., 1995). Program AlphaSim (Ward, 2000), a Monte Carlo simulation that is part of AFNI was used to determine cluster size and significance. Using an individual voxel probability threshold of $p=.001$, indicated that using a minimum cluster size of 36 original voxels (51 MNI transformed voxels) resulted in an overall significance of $p=$ .048. The activation map, thresholded using a cluster size of 51 voxels, for each group was overlaid onto an individual's T1 scan, transformed into MNI space, to help with localization of activation. For each group, age was added as a regressor and regions correlated with age were examined. For the ASD group, in a separate analysis, ADOS social + communication scores were added as regressors to examine regions correlated with the ADOS. Direct group comparison was done by using the transformed effect and standard error of the effect maps for all subjects. An image series of the effect maps for all subjects was made and sorted into blocks with members in each group ordered together. A block design GLM with regressors for each group type was then performed. We examined regions more active in the ASD group and regions more active in the control group. Peaks of activation were identified for each contrast using a cluster threshold of 51 MNI transformed voxels.

\section{RESULTS}

\section{Behavioral Performance}

All individuals were able to do the task easily and with only 1 practice session. Complete behavioral data were not available for 1 subject due to button box errors, however, during the practice run this subject made no errors. Accuracy measures for this subject were not included, but reaction time data were included for this subject for all trials in which a response was recorded. No subject made errors on more than 2 trials across both runs. For accuracy and reaction time data, see Table 2. To examine differences in accuracy and reaction time, 2-factor ANOVAs were done with group and task (semantic, perceptual) as factors and accuracy or reaction time as dependent variables. For accuracy, there were no significant effects of task or task by group interaction. There was a significant effect of group $(F(1,21)=$ $7.17, p=.014)$, with the ASD group having higher accuracy. Both groups' performances, however, were at ceiling. For reaction time, there was a significant effect of task $(F(1,22)=130.84, p<.001)$, demonstrating faster reac- 
Table 2. Mean accuracy presented as percent correct and reaction time in $\mathrm{ms}$ for the response-naming task and visual processing task for each group

\begin{tabular}{llcc}
\hline \hline & & \multicolumn{1}{c}{ Controls } & \multicolumn{1}{c}{ ASD } \\
\hline Semantic Task & Accuracy & $99.3(1.63)$ & $99.6(1.27)$ \\
& Reaction Time & $949.60(103.54)$ & $861.38(114.48)$ \\
Visual Task & Accuracy & $97.9(2.83)$ & $100.0(0.00)$ \\
& Reaction Time & $666.46(134.58)$ & $541.27(102.08)$ \\
\hline \hline
\end{tabular}

tion times for the visual than semantic task. There was also a significant group effect $(F(1,22)=7.66, p=.011)$ with the ASD group responding faster than controls for both tasks. Because of the design of the task, however, reaction time was not a measure of time to generate a response. Subjects were instructed and given time to think of their response prior to the word choices. They then chose the word that matched what they had generated. They also were not given specific instructions to respond as quickly as possible.

\section{Functional Activation - Individuals}

Every subject in both groups had activation in left frontal language areas and left temporal language regions with very little activation in homologous right hemisphere areas. For percent signal change there was a significant hemisphere effect $(F(2,21)=33.45, p<.001)$ and a significant group effect $(F(2,21)=15.36, p<.001)$. The hemisphere by group interaction was close to significant $(F(2,21)=3 \cdot 10, p=.066)$. Follow-up univariate tests indicated that for the hemisphere effect there was higher percent signal change in left regions than right for frontal $(F(1,22)=47.83, p<.001)$ and temporal $(F(1,22)=$ $47.11, p<.001)$ ROIs. The group difference was significant only for frontal ROIs $(F(1,22)=32.18, p<.001)$, indicating significantly higher percent signal change in ASD individuals compared to controls (Fig. 2). At the univariate level, the hemisphere by group interaction was significant for the frontal region $(F(1,22)=5.29, p=.031)$, with a larger difference between left and right hemispheres in controls than ASD.

Mean AQs are presented in Table 3. There was a significant group difference in degree of AQ $(F(2,21)=6.11$, $p=.008)$. Follow-up univariate tests revealed significant differences in frontal percent signal change AQ $(F(1,22)=$ $11.89, p=.002)$, demonstrating stronger AQ in controls than ASD.

See Table 4 for correlations in each group. After correcting for multiple comparisons, no correlations between percent signal change with CELF-III scores, age, or IQ were significant in either group. In the control group, there was a significant correlation between frontal and temporal percent signal change in the left hemisphere $(r=.934, p<$ $.001)$, but not in the right hemisphere. This correlation was

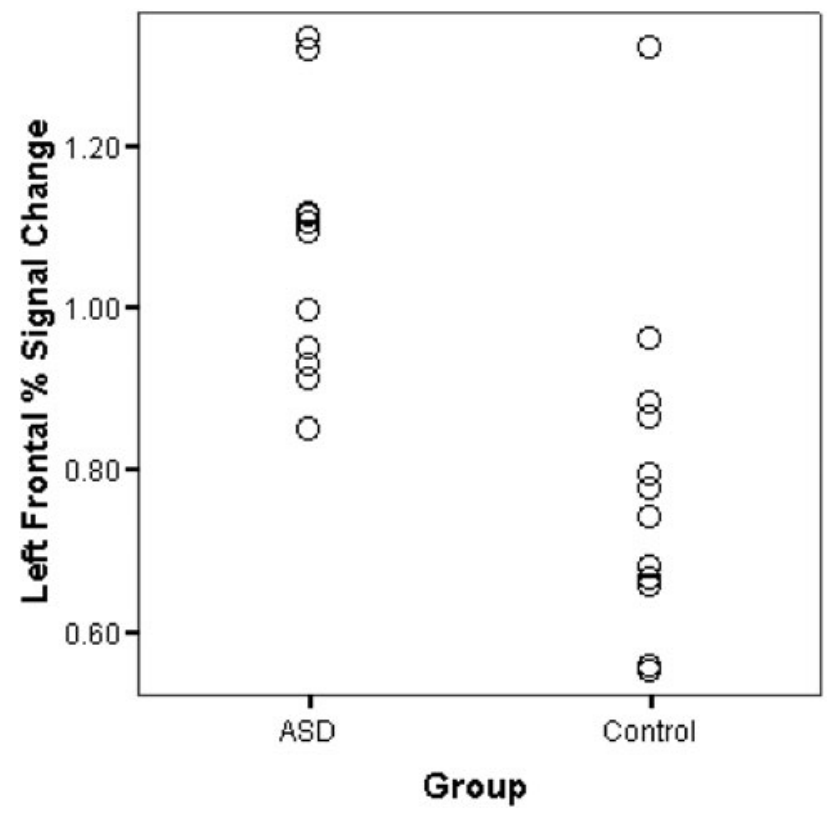

Fig. 2. Graph showing percent signal change of activation in left frontal language regions for each subject in each group.

not significant in either hemisphere in the ASD group (Fig. 3). Correlations with ADOS scores were also not significant.

\section{Functional Activation-Group}

For the control group, seven clusters of activation were identified (Table 5 and Fig. 4a). The largest cluster was in the left hemisphere in Broca's area; it included the pars triangularis, pars orbitalis, banks of the inferior frontal gyrus, and medial orbito-frontal regions. Large clusters were also in left anterior and posterior superior temporal regions. Another large cluster was in left temporal regions, which included the inferior temporal gyrus, fusiform gyrus, and parahippocampal area. In addition, clusters were present in left orbito-frontal cortex, left inferior temporal gyrus, and left superior pre-central gyrus. There were no regions correlated with age.

In the ASD group, there were eight clusters of activation (Table 6 and Fig. 4b). Again, the largest cluster was in the

Table 3. Mean (standard deviation) asymmetry quotient for each ROI in each group

\begin{tabular}{lcc}
\hline \hline & Controls $(n=12)$ & ASD $(n=12)$ \\
\hline Frontal \% Signal AQ & $.716(.421)$ & $.216(.273)$ \\
Temporal \% Signal AQ & $.509(.446)$ & $.507(.440)$ \\
\hline \hline
\end{tabular}


Table 4. Correlations ( $r$-and $p$-values) between percent signal change of each ROI with behavioral measures for each group

\begin{tabular}{|c|c|c|c|c|c|c|c|c|c|}
\hline & & \multicolumn{4}{|c|}{ Controls $(n=12)$} & \multicolumn{4}{|c|}{$\operatorname{ASD}(n=12)$} \\
\hline & & $\begin{array}{l}\text { Left frontal } \\
\% \text { signal }\end{array}$ & $\begin{array}{l}\text { Right frontal } \\
\% \text { signal }\end{array}$ & $\begin{array}{l}\text { Left temporal } \\
\% \text { signal }\end{array}$ & $\begin{array}{c}\text { Right temporal } \\
\% \text { signal }\end{array}$ & $\begin{array}{c}\text { Left Frontal } \\
\% \text { Signal }\end{array}$ & $\begin{array}{c}\text { Right Frontal } \\
\% \text { Signal }\end{array}$ & $\begin{array}{c}\text { Left Temporal } \\
\% \text { Signal }\end{array}$ & $\begin{array}{c}\text { Right Temporal } \\
\% \text { Signal }\end{array}$ \\
\hline \multirow[t]{2}{*}{ Age } & $r$ & -.550 & -.305 & -.632 & -.364 & .088 & .137 & -.230 & -.059 \\
\hline & $p$ & .064 & .336 & .027 & .245 & .786 & .672 & .471 & .856 \\
\hline \multirow[t]{2}{*}{ CELF Rec } & $r$ & .117 & -.629 & .175 & -.244 & .057 & -.116 & .378 & .151 \\
\hline & $p$ & .718 & .028 & .587 & .445 & .861 & .719 & .226 & .639 \\
\hline \multirow[t]{2}{*}{ CELF Exp } & $r$ & .144 & -.162 & .172 & .392 & .065 & -.272 & .459 & .117 \\
\hline & $p$ & .656 & .615 & .592 & .208 & .841 & .393 & .133 & .718 \\
\hline \multirow[t]{2}{*}{ K-BIT VIQ } & $r$ & .296 & -.631 & .167 & -.030 & -.030 & -.304 & .473 & .152 \\
\hline & $p$ & .350 & .028 & .605 & .927 & .925 & .337 & .120 & .636 \\
\hline \multirow[t]{2}{*}{ K-BIT NVIQ } & $r$ & -.079 & -.516 & -.177 & -.197 & -.173 & -.302 & .453 & .355 \\
\hline & $p$ & .808 & .086 & .581 & .540 & .590 & .340 & .139 & .258 \\
\hline \multirow[t]{2}{*}{ ADOS Com } & $r$ & - & - & - & - & .111 & .232 & -.257 & -.337 \\
\hline & $p$ & & & & & .730 & .469 & .419 & .283 \\
\hline \multirow[t]{2}{*}{ ADOS Social } & $r$ & - & - & - & - & .220 & -.069 & .162 & -.274 \\
\hline & $p$ & & & & & .493 & .831 & .615 & .388 \\
\hline \multirow[t]{2}{*}{ Left Frontal \% Signal } & $r$ & - & - & $.934 *$ & - & - & - & .272 & - \\
\hline & $p$ & & & .000 & & & & .393 & \\
\hline \multirow[t]{2}{*}{ Right Frontal \% Signal } & $r$ & - & - & - & .374 & - & - & - & -.065 \\
\hline & $p$ & & & & .231 & & & & .841 \\
\hline
\end{tabular}



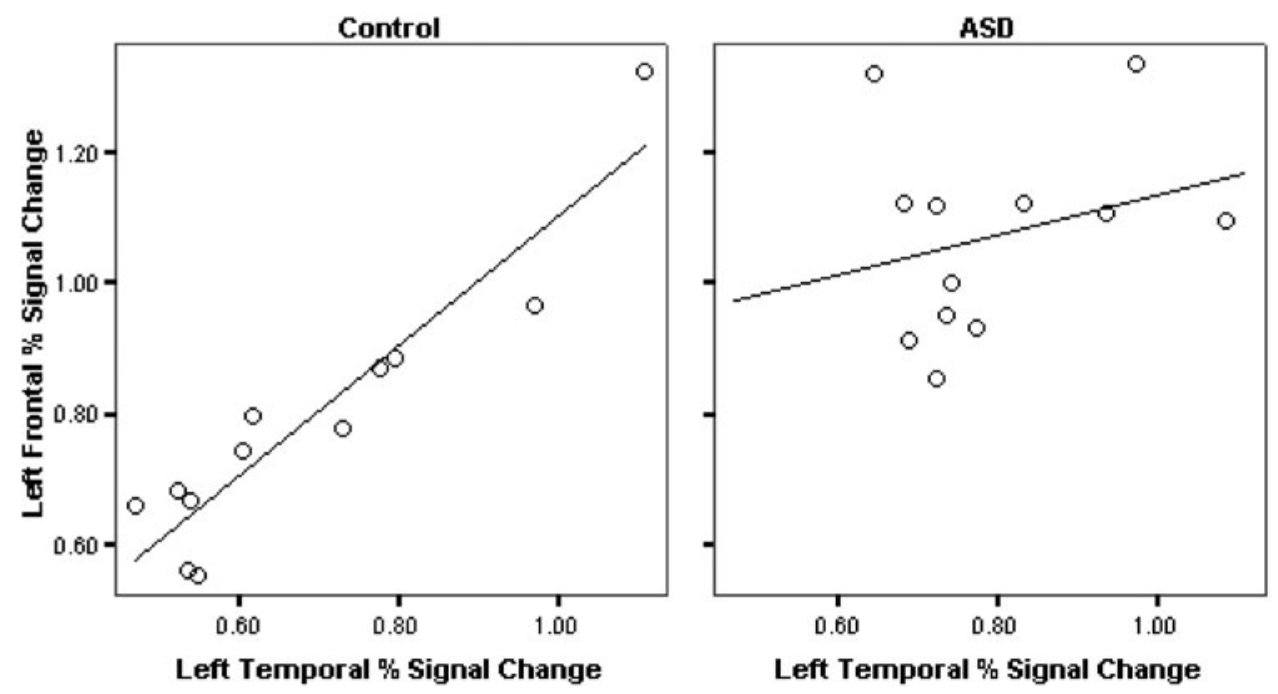

Fig. 3. Correlations between left frontal percent signal change with left temporal percent signal change in the control group and in the ASD group.

left hemisphere in Broca's area, including the pars triangularis, pars orbitalis, banks of the inferior frontal gyrus, insula, and orbito-frontal, extending into superior pre-central gyrus. A large cluster was also present in the anterior and posterior superior temporal gyrus, which included posterior middle and inferior temporal gyri. Clusters were also in left thalamus and caudate, left medial superior frontal gyrus, and right cerebellum. Activation was also in the left in the brainstem, parahippocampus, hippocampus and fusiform gyrus, and right lateral inferior frontal gyrus. There was 1 region correlated with age located in right lateral parietal/postcentral gyrus and no regions were correlated with ADOS scores.

When groups were directly contrasted, there was one small region near the posterior corpus callosum/cingulate that was more active in controls than the ASD group. ASD subjects, however, had more activation than controls in 11 clus- ters (Table 7). The biggest clusters were located in right inferior and middle frontal gyri and right middle temporal gyrus. Other clusters were in the left in inferior frontal gyrus, inferior temporal and fusiform gyri, pre-central gyrus, and posterior superior temporal gyrus. There were also clusters in left medial superior and middle frontal gyrus and medial Broca's area. Smaller clusters were found in the right in pre-central gyrus, orbito-frontal, and superior parietal regions.

\section{DISCUSSION}

During semantic processing, we found differences in activation between ASD and typically developing adolescents. The ASD group had significantly more activation in Broca's area, which was less lateralized compared to controls. In the left hemisphere, frontal and temporal activation was

Table 5. Regions of activation in the typically developing group for response-naming compared to visual processing task. Cluster size is in voxels. MNI coordinates are for peak activated voxel in each cluster

\begin{tabular}{|c|c|c|c|c|c|}
\hline \multicolumn{6}{|r|}{ Control group activations } \\
\hline \multicolumn{3}{|c|}{ MNI coordinates } & \multirow[b]{2}{*}{ Cluster size } & \multirow[b]{2}{*}{$t$-value } & \multirow[b]{2}{*}{ Anatomical region } \\
\hline$x$ & $y$ & $z$ & & & \\
\hline-50 & 25.0 & 14 & 778 & 6.51 & Left inferior frontal gyrus, pars triangularis, pars orbitalis, medial orbito-frontal \\
\hline-54 & -11.0 & -12 & 220 & 5.47 & Left anterior superior temporal gyrus \\
\hline-58 & -37.0 & 6 & 168 & 4.77 & Left posterior superior temporal gyrus \\
\hline-32 & -37.0 & -16 & 165 & 5.43 & Left inferior temporal gyrus, fusiform gyrus, parahippocampus \\
\hline-32 & 33.0 & -12 & 88 & 5.10 & Left medial orbito-frontal \\
\hline-36 & -13.0 & -40 & 64 & 4.42 & Left inferior temporal gyrus \\
\hline-44 & -.5 & 50 & 54 & 4.37 & Left superior pre-central gyrus \\
\hline
\end{tabular}


(a)
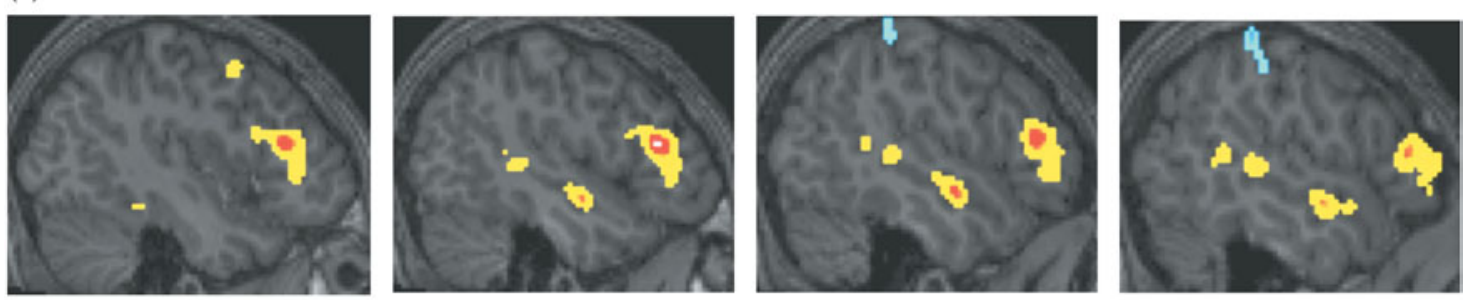

(b)
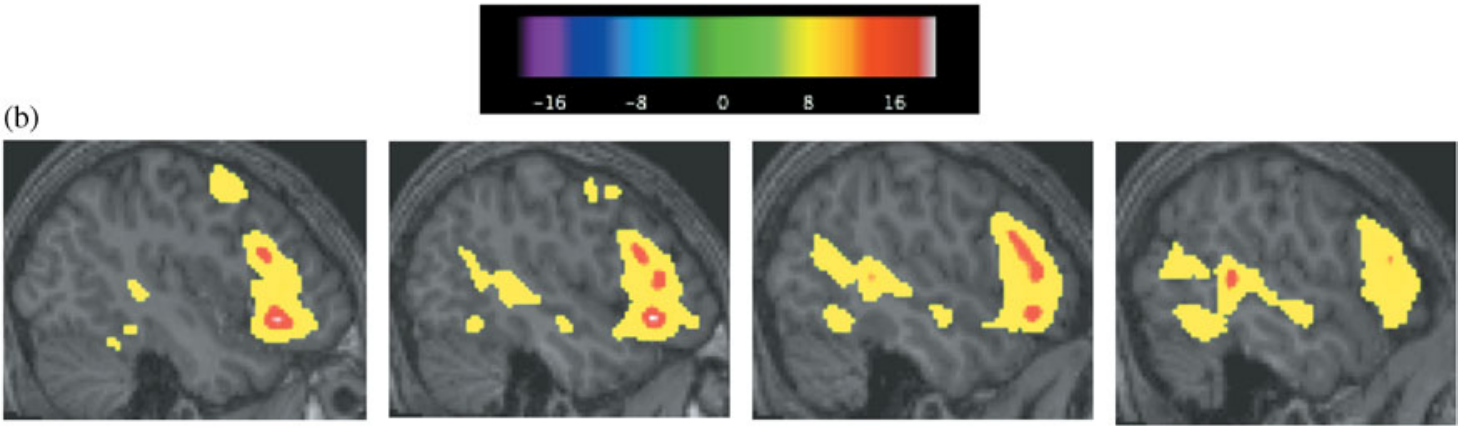

Fig. 4. (a) Sagittal slices showing control group activation of Broca's and Wernicke's areas during response-naming minus perceptual task. (b) The same sagittal slices showing Broca's and Wernicke's area activation in the ASD group for response-naming minus perceptual processing. Colder colors (blue, purple, black) indicate negative responses and hotter colors (yellow, red, white) indicate positive responses.

correlated in controls but not in ASD individuals. The ASD group relative to the typically developing group also had additional regions activated during semantic processing.

Broca's area is involved in semantic encoding and retrieval and on-line manipulation of semantic representations (Blumenfeld et al., 2006). Because of its critical role in language, Broca's has been examined, with structural and functional language studies demonstrating differences in ASD (Abell et al., 1999; de Fossé et al., 2004; Gaffrey et al., 2007; Harris et al., 2006; Herbert et al., 2002, 2005; Just et al., 2004; Kana et al., 2006; McAlonan et al., 2005). We predicted differences in this critical language area, however, we did not expect an increase in activation in ASD. There are important differences between our study and previous language studies, which may account for this discrepant finding. One difference is task performance. In the current study, both groups performed at ceiling levels, however, in some prior studies, the ASD group had significantly lower

Table 6. Regions of activation in the ASD group for response-naming compared to visual processing task. Cluster size is in voxels. MNI coordinates are for peak activated voxel in each cluster

\begin{tabular}{|c|c|c|c|c|c|}
\hline \multicolumn{6}{|r|}{ ASD group activations } \\
\hline \multicolumn{3}{|c|}{ MNI coordinates } & \multirow[b]{2}{*}{ Cluster size } & \multirow[b]{2}{*}{$t$-value } & \multirow[b]{2}{*}{ Anatomical region } \\
\hline$x$ & $y$ & $z$ & & & \\
\hline-48 & 23 & -10 & 4117 & 8.27 & $\begin{array}{l}\text { Left inferior frontal gyrus, pars triangularis, pars orbitalis, superior pre-central gyrus, } \\
\text { insula, orbito-frontal }\end{array}$ \\
\hline-62 & -47 & 8 & 1976 & 7.40 & $\begin{array}{l}\text { Left anterior and posterior superior temporal gyrus, posterior middle temporal gyrus, } \\
\text { posterior inferior temporal gyrus }\end{array}$ \\
\hline-8 & -17 & 12 & 741 & 6.09 & Left thalamus, caudate \\
\hline-4 & 7 & 60 & 605 & 7.63 & Left medial superior frontal gyrus \\
\hline 36 & -81 & -26 & 313 & 5.43 & Right cerebellum \\
\hline-8 & -21 & -10 & 256 & 4.94 & Left brainstem, parahippocampus, hippocampus \\
\hline-32 & -39 & -17 & 249 & 5.68 & Left fusiform gyrus \\
\hline 62 & 31 & 18 & 63 & 4.32 & Right lateral inferior frontal gyrus \\
\hline
\end{tabular}


Table 7. Regions of activation for ASD group $>$ Control group for response-naming compared to visual task. Cluster size is in voxels. MNI coordinates are for peak activated voxel in each cluster

\begin{tabular}{|c|c|c|c|c|c|}
\hline \multicolumn{6}{|c|}{ ASD $>$ Control group activations } \\
\hline \multicolumn{3}{|c|}{ MNI coordinates } & \multirow[b]{2}{*}{ Cluster size } & \multirow[b]{2}{*}{$t$-value } & \multirow[b]{2}{*}{ Anatomical region } \\
\hline$x$ & $y$ & $z$ & & & \\
\hline 62 & 31 & 20 & 388 & 3.75 & Right inferior/middle frontal gyrus \\
\hline 72 & -57 & -6 & 238 & 3.71 & Right middle temporal gyrus \\
\hline-54 & 19 & 18 & 196 & 3.97 & Left inferior frontal gyrus \\
\hline-62 & -65 & -8 & 163 & 3.73 & Left inferior temporal gyrus, fusiform gyrus \\
\hline-34 & 3 & 34 & 161 & 3.61 & Left pre-central gyrus \\
\hline-58 & -69 & 12 & 149 & 4.05 & Left posterior superior temporal gyrus \\
\hline-2 & 5 & 60 & 140 & 4.73 & Left medial superior/middle frontal gyrus \\
\hline-36 & 17 & -.25 & 105 & 3.43 & Left medial pars triangularis/pars opercularis \\
\hline 38 & 13 & 24 & 96 & 3.29 & Right pre-central gyrus \\
\hline 38 & 39 & -14 & 56 & 4.08 & Right orbito-frontal \\
\hline 42 & -71 & 56 & 55 & 3.37 & Right superior parietal \\
\hline
\end{tabular}

accuracy than controls (Gaffrey et al., 2007; Just et al., 2004). When 1 group is not as able to do the task, activation may not be a measure of regions involved in the task, but may reflect regions that are compensating for not being able to do the task or associated with errors (Bookheimer, 2000). Gaffrey and colleagues (2007) demonstrated some regions of activation that correlated with increasing semantic errors. In addition, behavioral studies have not found semantic deficits but rather point to differences in semantic organization, approaches, and/or use of semantic information. By using a task with ceiling performance, activation differences are not related to differences in task performance. The sample has also differed between studies. Previous studies have involved adults (Gaffrey et al., 2007; Harris et al., 2006; Just et al., 2004; Kana et al., 2006), whereas our study was comprised of adolescents, 11-19 years old. Studies of age effects on language activation have suggested differences, but results have been inconsistent (Gaillard et al., 2003; Holland et al., 2001; Schlaggar et al., 2002; Szaflarski et al., 2006; Wood et al., 2004). We only found one small region in the ASD group associated with age; however, our sample involved only adolescents and therefore included a small age range. Another important difference is the semantic task, with our task involving language generation. Other studies have involved making decisions about individual words (Gaffrey et al., 2007; Harris et al., 2006) or sentences (Just et al., 2004; Kana et al., 2006). Making decisions about single words may require limited semantic processing and does not require integration of information and sentence tasks are more complicated, involve understanding words in context, and may require syntactic processing. Our task involved semantic integration and word generation and Broca's area is particularly important in language production (Foundas, 2001).
Thus, task differences could account for our contrasting finding of increased Broca's activation and decreased lateralization of activation.

The lack of correlation between activation in left frontal and temporal language areas in the ASD group, suggests differences in communication between critical language areas, implying less efficient connectivity in ASD than in controls. Our finding supports Just and colleagues (2004) who were the first to show decreased functional connectivity during a language task in adults with autism. It is also consistent with a finding of decreased functional connectivity between language and visuospatial regions in ASD (Kana et al., 2006). Our finding also supports studies of white matter. Courchesne et al. (2001) found abnormalities in white matter development, with increased white matter in toddlers but decreased white matter in adolescents with ASD compared to controls. Similarly, Barnea-Goraly et al. (2004) found decreased integrity of white matter in ASD adolescents.

The more diffuse activation pattern in the ASD group is consistent with our hypothesis and previous behavioral findings. Because accuracy on the task was equivalent, these activation differences suggest differences in semantic organization or approach to semantic processing. Semantic information may be organized differently in individuals with ASD, resulting in different brain regions being used, which is in line with long-term memory (Toichi \& Kamio, 2003) and priming studies (Kamio et al., 2007) in ASD. Different approaches to the semantic task could also result in different regions being activated, which is consistent with priming studies showing increased priming to pictures (Kamio $\&$ Toichi, 2000) and correlations with non-verbal tasks (Toichi \& Kamio, 2001) in ASD. Imaging studies have also suggested different strategies in semantic processing. Kana 
et al. (2006) found that ASD individuals used the same regions to process high- and low-imagery sentences, whereas controls did not. Similarly, Gaffrey et al. (2007) found visual imagery regions activated during their semantic task in ASD, but not controls. Harris et al. (2006) also found decreased differences in activation between semantic and visual tasks in the ASD group than controls. The more diffuse activation in ASD could also be related to efficiency in semantic processing, especially given that the ASD group had significantly lower receptive and expressive language scores. We did not, however, have a behavioral measure of processing efficiency in this study to examine this possibility.

In summary, we found differences in activation between ASD and typically developing adolescents during a semantic task involving language production, which may reflect differences in semantic organization or approaches to the semantic task. There are several limitations to this study. One limitation is that we do not have a measure of processing efficiency. Although reaction time was collected, because of the task design, this was not a measure of time to generate a response and is therefore not a meaningful measurement. Another limitation is the relatively small sample size. Although, this sample size is similar to other fMRI studies of ASD, given the large variability in ASD, larger numbers of participants may be more revealing of within-group variability in activation patterns. Another potential limitation is that although some lower-functioning individuals with ASD were included, most of our subjects were high-functioning. Future studies should include larger more heterogeneous samples so that differences in activation related to age, functioning level, and language abilities within the ASD group could also be explored.

\section{ACKNOWLEDGMENTS}

This study was supported by a program project grant from the National Institute on Deafness and Other Communication Disorders (U19 DC 03610), which is part of the NICHD/NIDCD funded Collaborative Programs on Excellence in Autism, as well as funding for the GCRC at Boston University School of Medicine (M01RR0533). This study was also supported by NINDS F30 NS055511. The authors thank all of their research assistants and Lin Themelis for help with screening and scheduling the participants. They also extend their sincere gratitude to the children and families who participated in this study.

\section{REFERENCES}

Abell, F., Krams, M., Ashburner, J., Passingham, R., Friston, K., Frackowiak, R., Happé, F., Frith, C., \& Frith, U. (1999). The neuroanatomy of autism: A voxel-based whole brain analysis of structural scans. Neuroreport, 10, 1647-1651.

American Psychiatric Association (1994). Diagnostic and Statistical Manual of Mental Disorders. (4th ed.) Washington, DC: American Psychiatric Association Press.

Barnea-Goraly, N., Kwon, H., Menon, V., Eliez, S., Lotspeich, L., $\&$ Reiss, A.L. (2004). White matter structure in autism: Pre- liminary evidence from diffusion tensor imaging. Biological Psychiatry, 55, 323-326.

Blumenfeld, H.K., Booth, J.R., \& Burman, D.D. (2006). Differential prefrontal-temporal neural correlates of semantic processing in children. Brain and Language, 99, 226-235.

Boddaert, N., Belin, P., Chabane, N., Poline, J.B., Barthélemy, C., Mouren-Simeoni, M.C., Brunelle, F., Samson, Y., \& Zilbovicius, M. (2003). Perception of complex sounds: Abnormal pattern of cortical activation in autism. American Journal of Psychiatry, 160, 2057-2060.

Boddaert, N., Chabane, N., Belin, P., Bourgeois, M., Royer, V., Barthélemy, C., Mouren-Simeoni, M.C., Philippe, A., Brunelle, F., Samson, Y., \& Zilbovicius, M. (2004). Perception of complex sounds in autism: Abnormal auditory cortical processing in children. American Journal of Psychiatry, 161, 2117-2120.

Bookheimer, S. (2002). Functional MRI of language: New approaches to understanding the cortical organization of semantic processing. Annual Review of Neuroscience, 25, 151-188.

Bookheimer, S.Y. (2000). Methodological issues in pediatric neuroimaging. Mental Retardation and Developmental Disabilities Research Reviews, 6, 161-165.

Bookheimer, S.Y., Zeffiro, T.A., Blaxton, T., Malow, B.A., Gaillard, W.D., Sato, S., Kufta, C., Fedio, P., \& Theodore, W.H. (1997). A direct comparison of PET activation and electrocortical stimulation mapping for language localization. Neurology, 48, 1056-1065.

Courchesne, E., Karns, C.M., Davis, H.R., Ziccardi, R., Carper, R.A., Tigue, Z.D., Chisum, H.J., Moses, P., Pierce, K., Lord, C., Lincoln, A.J., Pizzo, S., Schreibman, L., Haas, R.H., Akshoomoff, N.A., \& Courchesne, R.Y. (2001). Unusual brain growth patterns in early life in patients with autistic disorder: An MRI study. Neurology, 57, 245-254.

Cox, R.W. \& Jesmanowicz, A. (1999). Real-time 3D image registration for functional MRI. Magnetic Resonance in Medicine, 42, 1014-1018.

de Fossé, L., Hodge, S.M., Makris, N., Kennedy, D.N., Caviness, V.S., Jr., McGrath, L., Steele, S., Ziegler, D.A., Herbert, M.R., Frazier, J.A., Tager-Flusberg, H., \& Harris, G.J. (2004). Language-association cortex asymmetry in autism and specific language impairment. Annals of Neurology, 56, 757-766.

Forman, S.D., Cohen, J.D., Fitzgerald, M., Eddy, W.F., Mintun, M.A., \& Noll, D.C. (1995). Improved assessment of significant activation in functional magnetic resonance imaging (fMRI): Use of a cluster-size threshold. Magnetic Resonance in Medicine, 33, 636-647.

Foundas, A.L. (2001). The anatomical basis of language. Topics in Language Disorders, 21, 1-19.

Gaffrey, M.S., Kleinhaus, N.M., Haist, F., Akshoomoff, N., Campbell, A., Courchesne, E., \& Müller, R.-A. (2007). A typical participation of visual cortex during word processing in autism: An fMRI study of semantic decision. Neuropsychologia, 45, 1672-1684.

Gaillard, W.D., Sachs, B.C., Whitnah, J.R., Ahmad, Z., Balsamo, L.M., Petrella, J.R., Braniecki, S.H., McKinney, C.M., Hunter, K., Xu, B., \& Grandin, C.B. (2003). Developmental aspects of language processing: fMRI of verbal fluency in children and adults. Human Brain Mapping, 18, 176-185.

Gervais, H., Belin, P., Boddaert, N., Leboyer, M., Coez, A., Sfaello, I., Barthélemy, C., Brunelle, F., Samson, Y., \& Zilbovicius, M. (2004). Abnormal cortical voice processing in autism. Nature Neuroscience, 7, 801-802. 
Harris, G.J., Chabris, C.F., Clark, J., Urban, T., Aharon, I., Steele, S., McGrath, L., Condouris, K., \& Tager-Flusberg, H. (2006). Brain activation during semantic processing in autism spectrum disorders via functional magnetic resonance imaging. Brain and Cognition, 61, 54-68.

Herbert, M.R., Harris, G.J., Adrien, K.T., Ziegler, D.A., Makris, N., Kennedy, D.N., Lange, N.T., Chabris, C.F., Bakardjiev, A., Hodgson, J., Takeoka, M., Tager-Flusberg, H., \& Caviness, V.S., Jr. (2002). Abnormal asymmetry in language association cortex in autism. Annals of Neurology, 52, 588-596.

Herbert, M.R., Ziegler, D.A., Deutsch, C.K., O’Brien, L.M., Kennedy, D.N., Filipek, P.A., Bakardjiev, A.I., Hodgson, J., Takeoka, M., Makris, N., \& Caviness, V.S., Jr. (2005). Brain asymmetries in autism and developmental language disorder: A nested whole-brain analysis. Brain, 128, 213-226.

Holland, S.K., Plante, E., Byars, A.W., Strawsburg, R.H., Schmithorst, V.J., \& Ball, W.S., Jr. (2001). Normal fMRI brain activation patterns in children performing a verb generation task. Neuroimage, 14, 837-843.

Just, M.A., Cherkassky, V.L., Keller, T.A., \& Minshew, N.J. (2004). Cortical activation and synchronization during sentence comprehension in high-functioning autism: Evidence of underconnectivity. Brain, 127, 1811-1821.

Kamio, Y., Robins, D., Kelley, E., Swainson, B., \& Fein, D. (2007). Atypical lexical/semantic processing in high-functioning autism spectrum disorders without early language delay. Journal of Autism \& Developmental Disorders, 37, 1116-1122.

Kamio, Y. \& Toichi, M. (2000). Dual access to semantics in autism: Is pictorial access superior to verbal access? Journal of Child Psychology and Psychiatry, 7, 859-867.

Kana, R.K., Keller, T.A., Cherkassky, V.L., Minshew, N.J., \& Just, M.A. (2006). Sentence comprehension in autism: Thinking in pictures with decreased functional connectivity. Brain, 129, 2484-2493.

Kaufman, A.S. \& Kaufman, N.L. (2004). Kaufman Brief Intelligence Test. (2nd ed.) Circle Pines, MN: AGS Publishing.

Knaus, T.A., Bollich, A.M., Corey, D.M., Lemen, L.C., \& Foundas, A.L. (2004). Sex-linked differences in the anatomy of perisylvian language cortex: A volumetric MRI study of graymatter volumes. Neuropsychology, 18, 738-747.

Knaus, T.A., Bollich, A.M., Corey, D.M., Lemen, L.C., \& Foundas, A.L. (2006). Variability in perisylvian brain anatomy in healthy adults. Brain and Language, 97, 219-232.

Knaus, T.A., Corey, D.M., Bollich, A.M., Lemen, L.C., \& Foundas, A.L. (2007). Anatomical asymmetries of anterior perisylvian speech-language regions. Cortex, 43, 499-510.

Lord, C., Risi, S., Lambrecht, L., Cook, E.H., Lenventhal, B.L., DiLavore, P.S., Pickles, A., \& Rutter, M. (2000). The autism diagnostic observation schedule_-generic: A standard measure of social and communication deficits associated with the spectrum of autism. Journal of Autism and Developmental Disorders, 30, 205-223.

Lord, C., Rutter, M., \& Le Couteur, A. (1994). Autism diagnostic interview-revised: A revised version of a diagnostic interview for caregivers of individuals with possible pervasive developmental disorders. Journal of Autism and Developmental Disorders, 24, 659-685.

McAlonan, G.M., Cheung, V., Cheung, C., Suckling, J., Lam, G.Y., Tai, K.S., Yip, L., Murphy, D.G.M., \& Chua, S.E. (2005). Mapping the brain in autism. A voxel-based MRI study of volumetric differences and intercorrelations in autism. Brain, 128, 268-276.
Mottron, L., Morasse, K., \& Belleville, S. (2001). A study of memory functioning in individuals with autism. Journal of Child Psychology and Psychiatry and Allied Disciplines, 42, 253-260.

Müller, R.-A., Behen, M.E., Rothermel, R.D., Chugani, D.C., Muzik, O., Mangner, T.J., \& Chugani, H.T. (1999). Brain mapping of language and auditory perception in high-functioning autistic adults: A PET study. Journal of Autism and Developmental Disorders, 29, 19-31.

Müller, R.-A., Chugani, D.C., Behen, M.E., Rothermel, R.D., Muzik, O., Chakraborty, P.K., \& Chugani, H.T. (1998). Impairment of dentato-thalamo-cortical pathway in autistic men: Language activation data from positron emission tomography. Neuroscience Letters, 245, 1-4.

Piro, J.M. (1998). Handedness and intelligence: Patterns of hand preference in gifted and nongifted children. Developmental Neuropsychology, 14, 619-630.

Schlaggar, B.L., Brown, T.T., Lugar, H.M., Visscher, K.M., Miezin, F.M., \& Petersen, S.E. (2002). Functional neuroanatomical differences between adults and school-age children in the processing of single words. Science, 296, 1476-1479.

Semel, E., Wiig, E.H., \& Secord, W.A. (1995). Clinical Evaluation of Language Fundamentals. (3rd ed.) San Antonio, TX: The Psychological Corporation, Harcourt Brace and Co.

Szaflarski, J.P., Holland, S.K., Schmithorst, V.J., \& Byars, A.W. (2006). fMRI study of language lateralization in children and adults. Human Brain Mapping, 27, 202-212.

Tager-Flusberg, H., Joseph, R., \& Folstein, S. (2001). Current directions in research on autism. Mental Retardation and Developmental Disabilities, 7, 21-29.

Tager-Flusberg, H., Paul, R., \& Lord, C.E. (2005). Language and communication in autism. In F. Volkmar, R. Paul, A. Klin, \& D.J. Cohen (Eds.), Handbook of autism and pervasive developmental disorder (3rd ed., pp. 335-364). New York: Wiley.

Toichi, M. \& Kamio, Y. (2001). Verbal association for simple common words in high-functioning autism. Journal of Autism \& Developmental Disorders, 31, 483-490.

Toichi, M. \& Kamio, Y. (2002). Long-term memory and levels-ofprocessing in autism. Neuropsychologia, 40, 964-969.

Toichi, M. \& Kamio, Y. (2003). Long-term memory in highfunctioning autism: Controversy on episodic memory in autism reconsidered. Journal of Autism \& Developmental Disorders, $33,151-161$.

Vigneau, M., Beaucousin, V., Hervé, P.Y., Duffau, H., Crivello, F., Houdé, O., Mazoyer, B., \& Tzourio-Mazoyer, N. (2006). Meta-analyzing left hemisphere language areas: Phonology, semantics, and sentence processing. Neuroimage, 30, 1414-1432.

Ward, B.D. (2000). Simultaneous Inference for fMRI Data [Computer software].

Witelson, S.F. \& Kigar, D.L. (1992). Sylvian fissure morphology and asymmetry in men and women: Bilateral differences in relation to handedness in men. Journal of Comparative Neurology, 323, 236-340.

Wood, A.G., Harvey, A.S., Wellard, R.M., Abbott, D.F., Anderson, V., Kean, M., Saling, M.M., \& Jackson, G.D. (2004). Language cortex activation in normal children. Neurology, 63, 1035-1044.

Worsley, K.J., Liao, C.H., Aston, J., Petre, V., Duncan, G.H., Morales, F., \& Evans, A.C. (2002). A general statistical analysis for fMRI data. Neuroimage, 15, 1-15. 


\section{APPENDIX}

\section{Stimuli Used in the Scanner}

\begin{tabular}{|c|c|c|c|c|c|}
\hline DBCD FMNTL RSVK & UPPER & lower & bpl mxwy stb & UPPER & lower \\
\hline gnc pqkst vdrh & UPPER & lower & QXJFGH KRNBW PCTBD & UPPER & lower \\
\hline bvmnld crtpjs lkjsdf & UPPER & lower & ybmcr cdlk rtpss & UPPER & lower \\
\hline CBRD SMSSM WTY & UPPER & lower & NKF DNNP GRTS & UPPER & lower \\
\hline $\begin{array}{l}\text { meal in morning } \\
\text { people live there } \\
\text { keeps hands warm } \\
\text { drink out of }\end{array}$ & $\begin{array}{l}\text { breakfast } \\
\text { store } \\
\text { gloves } \\
\text { plate }\end{array}$ & $\begin{array}{l}\text { dinner } \\
\text { house } \\
\text { socks } \\
\text { cup }\end{array}$ & $\begin{array}{l}\text { keeps neck warm } \\
\text { helps you see } \\
\text { tells the time } \\
\text { kids learn there }\end{array}$ & $\begin{array}{l}\text { scarf } \\
\text { glasses } \\
\text { lamp } \\
\text { hospital }\end{array}$ & $\begin{array}{l}\text { shoes } \\
\text { hat } \\
\text { clock } \\
\text { school }\end{array}$ \\
\hline tyrmnb cpldry wqkjdh & UPPER & lower & btkx mrwv ljpf & UPPER & lower \\
\hline YPFV CQT DGSG & UPPER & lower & MNVBCV HSJLDR PYRWL & UPPER & lower \\
\hline LVKBW NPPRT BDCS & UPPER & lower & TSHGT MVPLSR FJSDKL & UPPER & lower \\
\hline srtmnc jbwp kqcnv & UPPER & lower & FRD GKYH SPS & UPPER & lower \\
\hline $\begin{array}{l}\text { sit on it } \\
\text { wear on feet } \\
\text { people worship there } \\
\text { eat soup with }\end{array}$ & $\begin{array}{l}\text { desk } \\
\text { pants } \\
\text { church } \\
\text { spoon }\end{array}$ & $\begin{array}{l}\text { chair } \\
\text { shoes } \\
\text { store } \\
\text { knife }\end{array}$ & $\begin{array}{l}\text { buy food here } \\
\text { keeps rain off } \\
\text { sleep on it } \\
\text { people read them }\end{array}$ & $\begin{array}{l}\text { office } \\
\text { sweater } \\
\text { table } \\
\text { books }\end{array}$ & $\begin{array}{l}\text { store } \\
\text { umbrella } \\
\text { bed } \\
\text { radio }\end{array}$ \\
\hline RFD YGKH SSP & UPPER & lower & MCYBR DLCK PSRTS & UPPER & lower \\
\hline hgtst plmvsr sdfjkl & UPPER & lower & KNF NNDP RTGS & UPPER & lower \\
\hline VBMNCV JLHSDR RWPYL & UPPER & lower & pbl xwmy tsb & UPPER & lower \\
\hline kbtx wmrv pljf & UPPER & lower & jfqxgh nbkrw tbpcd & UPPER & lower \\
\hline $\begin{array}{l}\text { criminals go there } \\
\text { write with it } \\
\text { keeps head warm } \\
\text { people drive them }\end{array}$ & $\begin{array}{l}\text { library } \\
\text { pencil } \\
\text { shirt } \\
\text { cars }\end{array}$ & $\begin{array}{l}\text { jail } \\
\text { scissors } \\
\text { hat } \\
\text { planes }\end{array}$ & $\begin{array}{l}\text { jewelry for finger } \\
\text { borrow books from } \\
\text { lock door with } \\
\text { people fly them }\end{array}$ & $\begin{array}{l}\text { pin } \\
\text { library } \\
\text { key } \\
\text { planes }\end{array}$ & $\begin{array}{l}\text { ring } \\
\text { park } \\
\text { nail } \\
\text { buses }\end{array}$ \\
\hline
\end{tabular}

Bold indicates correct response. 